\title{
A prospective randomized controlled study comparing short-term outcomes of closure and non-closure of peritoneum during elective caesarean section
}

\author{
Santoshi Prabhu, Deepti N. Prasad*, Nigamanand Mishra, Vaishali Jadhav, Gayatri Savani
}

Department of Obstetrics and Gynaecology, Bhabha Atomic Research Centre, Chembur, Mumbai, Maharashtra, India

Received: 06 June 2021

Accepted: 22 June 2021

*Correspondence:

Dr. Deepti N. Prasad,

E-mail: docdeeptiprasad@gmail.com

Copyright: (c) the author(s), publisher and licensee Medip Academy. This is an open-access article distributed under the terms of the Creative Commons Attribution Non-Commercial License, which permits unrestricted non-commercial use, distribution, and reproduction in any medium, provided the original work is properly cited.

\begin{abstract}
Background: There is a rising trend of caesarean deliveries worldwide. Although a very commonly performed abdominal surgery, there is no ideal operative procedure in the literature. Several studies compared short term and longterm outcomes of closure and non-closure of peritoneum, but there is no consensus whether either procedure is beneficial to patients. Variability of results may be due to bias involved in these studies as two groups compared had different characteristics (including obstetrics and non-obstetrics laparotomies, elective and emergency caesareans, Pfannenstiel as well as vertical incisions; in the same study) which are likely to affect short term outcomes besides those due to peritoneal closer and non-closure. Aims and objectives of the study were to perform an unbiased assessment of short-term outcomes in elective LSCS in unscarred abdomens by Pfannenstiel incisions between closure (CG) and nonclosure of peritoneum (NCG).

Methods: Prospective randomised controlled study method used in the study.

Results: The operating time was significantly more $(\mathrm{p}=0.01)$ with difference of additional 10 minutes in CG with standard error of mean for time being 3.7688. Pain score was more in CG on post-operative day 1 and 2 ( $\mathrm{p}=0.0003$ and 0.008 respectively). Additional anaesthesia and analgesia were not needed in this group.

Conclusions: Apart from operative timing and pain score in early post-op period, there was no significant difference in short term outcomes between CG and NCG during elective caesarean section. Hence only long-term effects of these procedures need to be considered prior to recommending ideal steps of elective caesarean section procedure.
\end{abstract}

Keywords: Visual analogue scale, Non-closure, Peritoneum, Caesarean section

\section{INTRODUCTION}

There is a rising trend of caesarean deliveries worldwide. WHO, has considered $10-15 \%$ as ideal rate for Caesarean sections since 1985 . This rate varies in different countries, $40 \%$ countries had a rate of $<10 \%$ while $10 \%$ countries lie between $10-15 \%$ and $50 \%$ countries had rate $>15 \%$.

Being a very commonly performed abdominal surgery worldwide, we reviewed the literature for ideal operative method. Various techniques of performing caesarean section depending on clinical situation and surgeon's preferences were noted. ${ }^{1}$

In his original surgical approach of lower segment caesarean section (LSCS), Kerr in 1926, recommended closure of the visceral peritoneum along the uterine incision as well as the parietal. ${ }^{2}$ Maintaining anatomical integrity thus was thought to not only prevent adhesion formation between the uterus and surrounding structures but also to protect the peritoneal cavity from postpartum infection. 
Later, non-closure of peritoneum was suggested for reduction of operation duration, use of less analgesic, earlier return of bowel function, early post-operative recovery resulting in shortening of hospital stay. ${ }^{3,4}$

Several studies are conducted comparing short term and long-term outcomes of closure and non-closure of peritoneum, but there is no consensus whether either procedure is beneficial to patients. ${ }^{5-8}$

Variability of results may be due to bias involved in these studies, as two groups compared had different characteristics like obstetrics versus non-obstetrics laparotomies, indication for LSCS being elective or emergency, vertical versus Pfannenstiel incisions which are likely to affect short term outcome besides those due to peritoneal closer versus non closure. This motivated us to conduct unbiased study of short-term outcome in elective LSCS in unscarred abdomens with Pfannenstiel incisions.

\section{METHODS}

A prospective randomized controlled study was conducted in the department of obstetrics and gynaecology, at urban institute, on women undergoing elective LSCS between July 2017 and March 2021. Study was conducted after permission by institutional ethics and scientific committee.

Women with following conditions were excluded from the study: H/o previous lower abdominal surgery, severe anaemia $(\mathrm{Hb} \leq 7 \mathrm{gm} \%)$ which could affect wound status, presence of pelvic infection and adhesions, morbid obesity $(\mathrm{BMI} \geq 35)$ and presence of infective foci anywhere in the body suggested by fever and/or foul-smelling vaginal discharge.

Patients who were willing to participate after reading detailed participant information sheet were included in the study. Written informed consent was obtained from each patient for participation. By using computer generated random numbers, with the use of opaque sealed envelopes, the patients were randomly allocated to one of the two groups, closure group (CG) and non-closure (NCG). The envelopes were opened in sequence in the operating theatre, just before the start of the surgery and shown to the surgeon just before surgery. LSCS was performed through a Pfannenstiel incision. Uterus was closed with continuous number 1 polyglactin. In $\mathrm{CG}$, both parietal and visceral peritoneum was sutured with continuous absorbable 1-0 polyglactin. Rectus sheath was closed with a continuous number 1 nylon. The skin was approximated with staplers after insertion and fixation of subcutaneous mini-vacuum drain. Procedure of caesarean section was the same in NCG but without suturing of visceral and parietal peritoneum. Prophylactic antibiotic was given preoperatively after test dose with injection cefazolin (1 gm). Post-operatively, patients were managed in the same post-operative ward. The qualified OBGY specialist of department performed the surgery. Post-graduate students who did not perform the surgery and were blinded to the study groups made all postoperative assessment and management.

For analgesia, injection paracetamol (1 gm) intravenously, was given $8^{\text {th }}$ hourly, in the first 24 hours of surgery which was changed over to oral paracetamol (500 mg) 8 hourly after 24 hours for four days. Requirement of parenteral analgesia after 24 hours of surgery or oral analgesic beyond day 4 were considered as additional dose of analgesia and noted.

Post operatively urine culture was sent on day 4. Patients were discharged on day $4 / 5$ of surgery after removal of subcutaneous drain and doing check dressing of LSCS wound in absence of any other indication to stay inpatient for longer. Staples were removed on day 8 and wounds rechecked for infection on day 30 post operatively. Patients were asked to report to hospital or contact telephonically to the investigator in case of any discomfort or discharge from wound site.

Following outcomes were noted: anaesthesia time in minutes, operative time in minutes, post-operative pain measured by visual analogue score (VAS) chart, incidence of ileus, febrile morbidity (temperature more than 38 degree $\mathrm{C}$ on two occasions at least twelve hours apart, excluding the first postoperative day after ruling out other causes of fever), cystitis (urine culture sent on day 4 postoperatively), daily drain output was measured till the drain was removed, wound condition at discharge and on day 30 post-op, length of the hospital stay in days.

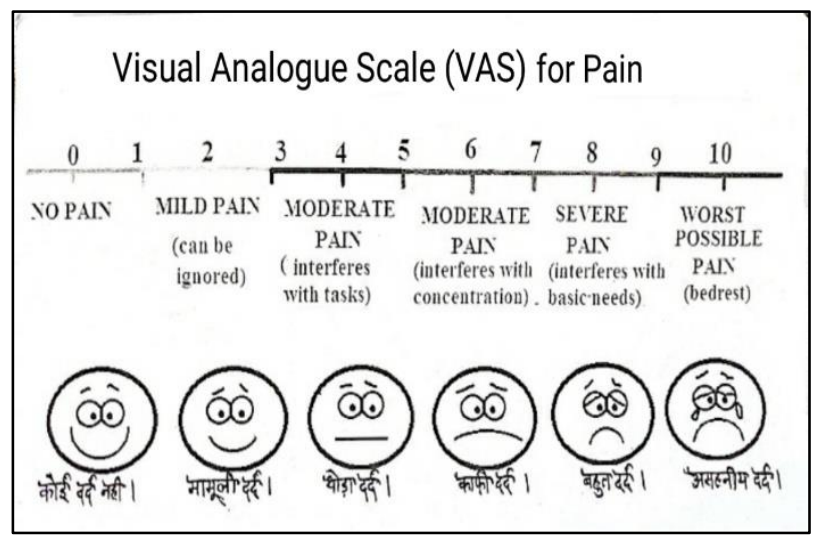

Figure 1: Visual analogue scale (VAS) for pain.

Post-operative pain was assessed by 10 -VAS (no pain $=0$, worst pain=10) (mild pain 1-3 score, moderate pain 4-7 score, severe pain $\geq 8$ score) at 24 hours after surgery and daily till the time of discharge. Patients were asked to indicate average intensity of pain they had experienced during the last 24 hours.

Sips of water and clear liquids were started after appearance of bowel sounds. Wound infection was diagnosed by presence of serous or purulent discharge from the skin incision with erythema and induration, with or without fever. 


\section{Statistical analysis}

Statistical analysis was done using SPSS version 20.0 (SPSS inc. Chicago in USA). Significance of difference, if any, in the observations made of variables were studied in control/subject groups, in numbers or averages determined using student $\mathrm{t}$ test. $\mathrm{P}<0.05$ was considered statistically significant.

\section{RESULTS}

Total 80 women were included in the study. Out of these 75 could follow up to 30 days post-partum. There were 38 patients in NCG and 37 patients in CG.

The average gestational age in weeks (Table 1) in NCG was $38.45 \pm 1.8$ and GG 38.4 \pm 1.31 . There was no significant difference $(\mathrm{p}=0.89)$ in gestational age in both groups.

Table 1: Distribution of cases as per average gestational age in weeks.

\begin{tabular}{|lcl|}
\hline $\begin{array}{l}\text { Variables } \\
\text { Average GA in }\end{array}$ & Non closure & \multicolumn{1}{c|}{ Closure } \\
weeks & $38.45 \pm 1.8$ & $38.4 \pm 1.31$ \\
\hline $\begin{array}{l}\text { P value } 0.89, \\
\text { not statistically significant. }\end{array}$
\end{tabular}

The average anaesthesia time in minutes (Table 2) in NCG was $77.1 \pm 15.0$ and CG $82.35 \pm 16.2$. There was no significant difference $(\mathrm{p}=0.142)$ in anaesthesia time in both groups.

Table 2: Distribution of cases according to anaesthesia time in minutes.

\begin{tabular}{|lllll|}
\hline $\begin{array}{l}\text { Anaesthesia } \\
\text { time (min) }\end{array}$ & $<60$ & $\begin{array}{l}60- \\
90\end{array}$ & $\begin{array}{l}90- \\
120\end{array}$ & $\begin{array}{l}\text { A verage } \\
\text { time (min) }\end{array}$ \\
\hline $\begin{array}{l}\text { Non closure } \\
\text { (cases) }\end{array}$ & 9 & 22 & 2 & $77.1 \pm 15.0$ \\
$\begin{array}{l}\text { Closure } \\
\text { (cases) }\end{array}$ & 5 & 28 & 4 & $82.35 \pm 16.2$ \\
\hline
\end{tabular}

$\mathrm{P}=0.142$, not statistically significant.

The average operative time in minutes (Table 3) in NCG was $50.63 \pm 15.62$ and $C G \quad 60.4 \pm 17$. There was no significant difference $(\mathrm{p}=0.01)$ in operative time in both groups.

Table 3: Distribution of cases according to operative time in minutes.

\begin{tabular}{|lllll|}
$\begin{array}{l}\text { Operative } \\
\text { time (min) }\end{array}$ & $<60$ & $\begin{array}{l}60- \\
90\end{array}$ & $\begin{array}{l}90- \\
120\end{array}$ & $\begin{array}{l}\text { Average } \\
\text { time (min) }\end{array}$ \\
$\begin{array}{l}\text { Non closure } \\
\text { (cases) }\end{array}$ & 29 & 8 & 1 & $50.63 \pm 15.62$ \\
\hline $\begin{array}{l}\text { Closure } \\
\text { (cases) }\end{array}$ & 23 & 10 & 4 & $60.4 \pm 17$ \\
\hline
\end{tabular}

$\mathrm{P}=0.01$, statistically significant.
Table 4 shows distribution of cases as per pain score measured by VAS in NCG. The average score was $7.05 \pm 1.59,5.26 \pm 1.89,3.89 \pm 1.41$ and $2.47 \pm 1.28$ on day 1 , 2,3 and 4 , respectively.

Table 4: Distribution of cases as per pain score measured by VAS: non closure.

\begin{tabular}{|lllll|}
\hline VAS & Day 1 & Day 2 & Day 3 & Day 4 \\
\hline Mild & 0 & 5 & 15 & 26 \\
\hline Moderate & 17 & 25 & 23 & 10 \\
\hline Severe & 21 & 8 & 0 & 0 \\
\hline Average & $7.05 \pm$ & $5.26 \pm$ & $3.89 \pm$ & $2.47 \pm$ \\
score & 1.59 & 1.89 & 1.41 & 1.28 \\
\hline
\end{tabular}

Table 5 shows distribution of cases as per pain score measured by VAS in CG. The average score was $78.40 \pm 1.5,6.32 \pm 1.58,4.21 \pm 1.68$ and $3.08 \pm 1.87$ on day 1 , 2, 3 and 4, respectively. Significantly higher pain score was observed on day 1 and 2 in CG (p=0.0003 and 0.008 respectively). On day 3 and 4 there was no significant difference in pain score observed in both the groups ( $\mathrm{p}=0.37$ and 0.102 , respectively).

Table 5: Distribution of cases as per pain score measured by VAS: closure.

\begin{tabular}{|lllll|}
\hline VAS & Day 1 & Day 2 & Day 3 & Day 4 \\
\hline Mild & 1 & 2 & 10 & 25 \\
\hline Moderate & 6 & 23 & 26 & 12 \\
\hline Severe & 30 & 12 & 1 & 0 \\
\hline Average & $8.40 \pm$ & $6.32 \pm$ & $4.21 \pm$ & $3.08 \pm$ \\
score & 1.5 & 1.58 & 1.68 & 1.87 \\
\hline P values & 0.0003, & 0.008, & 0.37, & 0.102, \\
& *sign. & sign. & not sign. & not sign. \\
\hline
\end{tabular}

*Sign=Significant.

The average subcutaneous drain output in ml (Table 6) in CG on day $1,2,3$ and 4 was $11.64 \pm 6.36$ $9.75 \pm 4.74,5.59 \pm 3.39$ and $3.35 \pm 1.75$. The same in NCG $15 \pm 11.81,11.89 \pm 7.62,5.84 \pm 3.89$ and $3.47 \pm 2.96$. There was no significant difference in day wise drain output in both the groups. $\mathrm{P}=0.08,0.15,0.76$ and 0.83 , respectively.

Table 6: Distribution of cases according to average drain output.

\begin{tabular}{|llll|}
\hline Days & $\begin{array}{l}\text { Average } \\
\text { D/O closure }\end{array}$ & $\begin{array}{l}\text { Average } \\
\text { D/O non } \\
\text { closure }\end{array}$ & P values \\
\hline $\mathbf{1}$ & $11.64 \pm 6.36$ & $15 \pm 11.81$ & $\begin{array}{l}0.08, \text { not } \\
\text { significant }\end{array}$ \\
\hline $\mathbf{2}$ & $9.75 \pm 4.74$ & $11.89 \pm 7.62$ & $\begin{array}{l}0.15, \text { not } \\
\text { significant }\end{array}$ \\
\hline $\mathbf{3}$ & $5.59 \pm 3.39$ & $5.84 \pm 3.89$ & $\begin{array}{l}0.76, \text { not } \\
\text { significant } \\
0.83, \text { not } \\
\text { significant }\end{array}$ \\
\hline $\mathbf{4}$ & $3.35 \pm 1.75$ & $3.47 \pm 2.96$ & \begin{tabular}{l} 
ignifican \\
\hline
\end{tabular} \\
\hline
\end{tabular}


The total stay in hospital in days (Table 7) in NCG was 4.86 \pm 0.77 and $\mathrm{CG}$ was 5.05 \pm 0.32 . No significant difference in hospital stay in both the groups $(\mathrm{p}=0.169)$.

Table 7: Distribution of cases according to total stay in hospital in days.

\begin{tabular}{|ll|l|}
\hline Days & Non closure & Closure \\
\hline $\mathbf{5}$ & 2 & 3 \\
\hline $\mathbf{5}$ & 36 & 34 \\
\hline Average & $4.86 \pm 0.77$ & $5.05 \pm 0.32$ \\
\hline
\end{tabular}

$\mathrm{P}=0.169$, not statistically significant.

Other short-term morbidities (Table 8) like fever, paralytic ileus, urine infection or wound infection was not observed in both NCG and CG.

Table 8: Distribution of cases according to other short-term morbidities.

\begin{tabular}{|ll|l|}
\hline Morbidity & Non closure & Closure \\
\hline Fever & Nil & Nil \\
\hline Paralytic ileus & Nil & Nil \\
\hline Urine infection & Nil & Nil \\
\hline Wound infection & Nil & Nil \\
\hline
\end{tabular}

Fever, paralytic ileus, urine infection, wound infection was not observed in both NCG and CG.

\section{DISCUSSION}

Peritoneum is composed of layer of mesothelium supported by thin layer of connective tissue. It is one continuous sheet forming two layers and potential space between them is called peritoneal cavity. The outer layer called parietal peritoneum is attached to the abdominal and pelvic wall. The inner layer called visceral peritoneum is wrapped around the visceral organs. During caesarean section, the peritoneal surfaces need to be breached before uterine incision.

Kerr in 1926, recommended closure of the visceral peritoneum along the uterine incision as well as the parietal. ${ }^{2}$ The reasons cited for peritoneal closure includes restoration of anatomy and thereby reduction in infection by maintaining anatomical barrier, reapproximation of tissues, reduction of adhesions, haemorrhage and wound dehiscence.

Studies have reported adhesion formation as a long-term complication when visceral and parietal peritoneum is left un-sutured. Closure of the peritoneum is strongly recommended by some authors in order to prevent thick adhesion formation involving the anterior uterine wall and the muscular layer, often encountered at the time of repeat caesarean sections. ${ }^{9,10}$ Choudhary et al reported cumbersome surgeries in patients who had non closure of peritoneum in previous surgeries. The operating time was longer due to dense omento-facial, bladder and bowel adhesions. They observed more blood loss and postoperative periods were turbulent with longer hospital stays in these patients. ${ }^{11}$ Lyell et al found that parietal peritoneal closure at primary caesarean delivery was 5fold protective against all adhesions and 3-fold protective against dense adhesions. ${ }^{12}$ Thereby confirming long term better outcome in $\mathrm{CG}$.

Reasons cited for non-closure of the peritoneum includes; reduction of operation duration, use of less analgesic, earlier return of bowel function, early post-operative recovery resulting in shortening of hospital stay. As postoperative pain can cause unpleasant physiological responses including ileus, increased usage of analgesics, increased hospital stays and delayed breast feeding, nonclosure was considered beneficial. ${ }^{3-6}$

Our study included women with no history of previous abdominal surgeries and undergoing elective LSCS with Pfannenstiel incisions. All women were in both the group were matched for age.

Total 80 women were included in the study. Out of these 75 could follow up to 30 days post-partum. There were 38 patients in NCG and 37 patients in CG. The average gestational age in weeks in both the groups was similar i.e., NCG was $38.45 \pm 1.8$ weeks and CG, 38.4 \pm 1.31 weeks $(\mathrm{p}=0.89, \mathrm{NS})$.

All women were operated under spinal anaesthesia. An average duration in NCG was 77.1 \pm 15.0 minutes and CG was $82.35 \pm 16.2 \min (\mathrm{p}=0.142$, NS).

The operating time was significantly more when peritoneum was closed as compared to when peritoneum was not closed $(p=0.01)$, difference of additional 10 minutes was required in $\mathrm{CG}$ with standard error of mean for time being 3.7688. Similar finding was reported by Cheong et al in $2001^{5}$ with difference of approximately 10 minutes between two groups. In a randomized double blinded clinical trial Tabasi et al in 2013 reported difference of 6.89 minutes between two groups. ${ }^{6}$ A systemic review by Bamigboye et al also revealed reduction in operating time in NCG by 7.33 minutes. ${ }^{8}$ All cases including $\mathrm{CG}$ were completed well within spinal anaesthesia time requiring no additional supplementation.

In the Cochrane collaboration 2014, 16 trials involving 15,480 women in analysis of CG and NCG of both peritoneal layers also found that operating time was significantly less in NCG, by 5.81 minutes. $^{8}$

In our study we found that pain score was more in cases of peritoneal closure as compared to NCG on post-operative day 1 and 2 ( $\mathrm{p}=0.0003$ and 0.008 respectively) although requirement of analgesia between two groups was not different. However, by day 3 pain score was not different.

Huchon et al in 2005 studied CG or NCS of the peritoneum at gynaecological operations and effect on postoperative pain. ${ }^{3}$ They reported no significant difference in analgesic requirements between two groups in the postoperative 
period. However, less pain and low VAS scores were evident especially after postoperative $2^{\text {nd }}$ and $48^{\text {th }}$ hours in the NCG. Study by Ying-Cheong et al in 2001 found no difference in pain score between two groups while study by Tabasi et al in 2013 found pain score as assessed by VAS was significantly lower in NCG. ${ }^{5,6}$ Also, study by Nagele in 1996 found decreased pain score in $\mathrm{NCG}^{7}$

The parietal peritoneum is innervated by somatic and visceral afferent nerves and is sensitive to touch, pressure, cutting and temperature. Any harmful stimulus is perceived as a localized, sharp pain. Although visceral peritoneum itself is not innervated, the sub-mesothelial tissue is supplied by the autonomous nerve system. This layer responds to traction and pressure but not to cutting or electrostimulation. Suturing peritoneum tends to cause inflammation and foreign body reactions to suture material resulting in ischemia and necrosis. This possibly explains the high pain score in peritoneal CG early in post-operative days which was then same in both groups' day 3 onwards.

There was no significant difference observed in subcutaneous drain output in both the groups.

Cochrane database reported no difference in postoperative febrile and infectious morbidity in both the group. ${ }^{8}$ In our study postoperative fever, paralytic ileus, urine infection, wound infection was not observed in any case of either group. This can be contributed to inclusion criteria: as elective procedure, unscarred abdomen as well as use of prophylactic antibiotic for all patients.

Similar to the reports by Ying-Cheon et al and Zohreh et al there was no significant difference observed in our study in length of hospital stay in days in either group. ${ }^{5,6}$ Cochrane database reported length of hospital stay in days was less in NCG; the difference was not statistically significant. $^{8}$

Our study concluded, apart from minimal reduction in operating time and pain score on first two days, there is no significant difference in short term morbidity between peritoneal CG and NCG. Although operating time was on an average 10 min more but no supplementary anaesthesia was required for additional step of peritoneal closure.

Additional analgesic for postoperative pain management was not required in CG. In none of patients oral feed was delayed or had to be modified as suggested by few studies

\section{Limitations}

Study was limited to elective cases only for more conclusive evidence; emergency cases also need to be evaluated.

\section{CONCLUSION}

While deriving ideal method of abdominal closure, for unreasonable short term small disadvantages long term benefits of peritoneal closure should not be ignored. Long term follows up of these cases is necessary regarding adhesion formation, intraoperative blood loss, postoperative recovery at the time of next laparotomies. Long term follow ups during subsequent surgery might help us to more conclusively to know benefit of one technique over other.

\section{ACKNOWLEDGMENTS}

Author would like to thanks to Dr. Jai Singh Yadav (DNB Resident) and Dr. Shalini Jha (RMO) for data maintenance.

\section{Funding: No funding sources \\ Conflict of interest: None declared \\ Ethical approval: The study was approved by the Institutional Ethics Committee}

\section{REFERENCES}

1. Hauth JC, Owen J, Davis RO. Transverse uterine incision closure. One versus two layers. Am J Obstet Gynecol. 1992;167:1108-11.

2. Kerr JMM. The technic of Cesarean section, with special reference to the lower uterine segment incision. Am J Obstet Gynecol. 1926;12:729-34.

3. Huchon C, Raiffort C, Chis C, Messaoudi F, Jacquemot MC, Panel P. Caesarean section: closure or non-closure of peritoneum? A randomized trial of postoperative morbidity. Gynecol Obstet Fertil. 2005;33(10):745-9.

4. Bamigboye AA, Hofmeyr GJ. Non-closure of peritoneal surfaces at caesarean section-a systematic review. S Afr Med J. 2005;95(2):123-6.

5. Cheong YC, Bajekal N, Li TC. Peritoneal closure to close or not to close. Hum Reprod. 2001;16(8):154852.

6. Tabasi Z, Mahdian M, Abedzadeh-Kalahroudi M. Closure or Non-Closure of Peritoneum in Cesarean Section: Outcomes of Short-Term Complications. Arch Trauma Res. 2013;1(4):176-9.

7. Nagele F, Karas H, Spitzer D, Staudach Al, Karasegh $\mathrm{S}$, Beck A et al. Closure or non-closure of the visceral peritoneum at cesarean delivery. American J Obst Gyn. 1996;174(4):1366-70.

8. Bamigboye AA, Hofmeyr GJ. Closure versus non closure of the peritoneum at caesarean section: shortand long-term outcome. Cochrane Database Syst Rev. 2014;11;(8):CD000163.

9. Cheong YC, Premkumar G, Metwally M, Peacock JL, Li TC. To close or not to close? A systematic review and a meta-analysis of peritoneal nonclosure and adhesion formation after caesarean section. Eur $\mathrm{J}$ Obstet Gynecol Reprod Biol. 2009;147(1):3-8.

10. Al-Asmari N, Tulandi $\mathrm{T}$. The relevance of postcesarean adhesions. Surg Technol Int. 2012;22:17781.

11. Choudhary A, Bansal N. Non closure of parietal peritoneum at cesarean section and adhesion 
formation. Int J Reprod Contracept Obstet Gynecol. 2013;2:406-9.

12. Lyell DJ, Chaughey AB, Hu E, Daniels K. Peritoneal closure at primary cesarean delivery and adhesions. Obstet Gynecol. 2005;106(2):275-80.
Cite this article as: Prabhu S, Prasad DN, Mishra N, Jadhav V, Savani G. A prospective randomized controlled study comparing short-term outcomes of closure and non-closure of peritoneum during elective caesarean section. Int J Reprod Contracept Obstet Gynecol 2021;10:2656-61. 